\title{
Neurological aspects of anhidrosis: differential diagnoses and diagnostic tools
}

\author{
Kee Hong Park ${ }^{1}$ and Ki-Jong Park ${ }^{2,3}$ \\ 'Department of Neurology, Gyeongsang National University Hospital, Jinju, Korea \\ ${ }^{2}$ Department of Neurology, Gyeongsang National University Changwon Hospital, Changwon, Korea \\ ${ }^{3}$ Department of Neurology, Gyeongsang National University School of Medicine, Jinju, Korea
}

Received: June 21, 2018

Revised: August 7, 2018

Accepted: August 13, 2018

\section{Correspondence to}

\section{Ki-Jong Park}

Department of Neurology, Gyeongsang National University School of Medicine, 79

Gangnam-ro, Jinju 52727, Korea

Tel: $+82-55-214-3810$

Fax: +82-55-214-3255

E-mail: pkjong@gnu.ac.kr

\section{ORCID}

\section{Kee Hong Park}

http://orcid.org/0000-0001-5724-7432

\section{Ki-Jong Park}

http://orcid.org/0000-0003-4391-6265

Anhidrosis refers to the condition in which the body does not respond appropriately to thermal stimuli by sweating. Sweating plays an important role in maintaining the body temperature, and its absence should not be overlooked since an elevated body temperature can cause various symptoms, even leading to death when uncontrolled. The various neurological disorders that can induce anhidrosis make a detailed neurological evaluation essential. The medication history of the patient should also be checked because anhidrosis can be caused by various drugs. The tests available for evaluating sweating include the quantitative sudomotor axon reflex sweat test, thermoregulatory sweat test, sympathetic skin response, and electrochemical skin conductance. Pathological findings can also be checked directly in a skin biopsy. This review discusses the differential diagnosis and evaluation of anhidrosis.

Key words: Anhidrosis; Sweating; Autonomic nervous system

\section{INTRODUCTION}

Sweating is controlled by the autonomic nervous system and performs an important function in keeping the body temperature constant. However, sweating problems are easily missed during patient examinations. In contrast to hyperhidrosis rarely having fatal consequences, anhidrosis can be lethal. ${ }^{1}$ Since anhidrosis can also lead to symptoms such as weakness, headache, dizziness, and pricking pain, ${ }^{2}$ patients may visit neurology clinics with these as their chief complaints. It is especially important to consider the possibility of anhidrosis when such symptoms are experienced in hot conditions or during exercise. It is also important for neurologists to understand that anhidrosis can be caused by various neurological disorders. 


\section{Physiology of sweating}

Sweat glands are divided into eccrine, apocrine, apoeccrine, and sebaceous glands. ${ }^{3}$ The eccrine glands play an important role in regulating the body temperature in response to stress and thermal stimuli. ${ }^{4}$ Unlike eccrine glands, apocrine glands are distributed within certain body areas, such as the axilla, genital area, and areolae. Eccrine glands are innervated by cholinergic nerve fibers, whereas apocrine glands are innervated by adrenergic nerve fibers. When the body temperature exceeds the threshold set by the preoptic area of the hypothalamus, a signal is sent via the tegmentum of the pons and lateral reticular substance of the medulla to the intermediolateral cell column of the spinal cord. The preganglionic fibers exiting the ventral horn synapse with the postganglionic fibers in the sympathetic chain, and so the signal will then stimulate the sweat glands. ${ }^{1}$ The postganglionic fibers are unmyelinated sympathetic C-fibers that release acetylcholine to activate M3 muscarinic receptors on the sweat glands. The characteristics of sweating are affected by numerous factors including age, sex, and environmental fac- tors such as humidity, diet, and time, and these factors need to be accounted for when evaluating sweating.

\section{Causes of anhidrosis}

\section{Drugs}

Anhidrosis can be caused by various drugs that many patients who present at neurological clinics may be taking, and so it is essential to check the medication history of such patients. In addition, the taking of certain medications needs to be stopped before performing an autonomic function test, because they can cause false-positive results suggestive of sudomotor dysfunction. ${ }^{5}$ The most-representative class of drugs is anticholinergics, which inhibit sweating by preventing the activation of sweat glands by acetylcholine. Other drugs that inhibit sweating are listed in Table $1 .{ }^{6}$

\section{Central nervous system disorders}

Multiple system atrophy (MSA) is characterized by autonomic dysfunction, parkinsonism, ataxia, and pyramidal signs.

Table 1. Drugs that can cause hypohidrosis ${ }^{6}$

\begin{tabular}{|c|c|c|}
\hline Drug class & Drugs & Mechanism \\
\hline Anticholinergics & $\begin{array}{l}\text { Atropine, belladonna, dicycloverine, glycopyrrolate, } \\
\text { hyoscyamine, propantheline }\end{array}$ & Antimuscarinic effect \\
\hline Antidepressants (tricyclics) & $\begin{array}{l}\text { Amitriptyline, clomipramine, desipramine, doxepin, } \\
\text { imipramine, nortriptyline, protriptyline }\end{array}$ & Antimuscarinic effect \\
\hline Antiepileptics & Topiramate, zonisamide, carbamazepine & $\begin{array}{l}\text { Carbonic anhydrase inhibition (topiramate and } \\
\text { zonisamide) } \\
\text { Central anticholinergic effect (carbamazepine) }\end{array}$ \\
\hline Antihistamines & Cyproheptadine, diphenhydramine, promethazine & Antimuscarinic effect \\
\hline Antihypertensives & Clonidine & Central adrenergic effect \\
\hline Antipsychotics and antiemetics & $\begin{array}{l}\text { Chlorpromazine, clozapine, olanzapine, thioridazine, } \\
\text { quetiapine }\end{array}$ & Antimuscarinic effect \\
\hline Antivertigo drugs & Meclizine, scopolamine & Antimuscarinic effect \\
\hline Bladder antispasmodics & Darifenacin, oxybutynin, solifenacin, tolterodine & Antimuscarinic effect \\
\hline Gastric antisecretory drugs & Propantheline & Antimuscarinic effect \\
\hline Muscle relaxants & Cyclobenzaprine, tizanidine & $\begin{array}{l}\text { Uncertain, but possibly inhibition of spinal excitatory } \\
\text { interneurons; possibly both central and peripheral } \\
\text { antimuscarinic effects }\end{array}$ \\
\hline Neuromuscular paralytics & Botulinum toxins & $\begin{array}{l}\text { Cleavage of SNAP-25 inhibiting presynaptic release of } \\
\text { acetylcholine }\end{array}$ \\
\hline Opioids & $\begin{array}{l}\text { Fentanyl, hydrocodone, methadone, morphine, } \\
\text { oxycodone }\end{array}$ & $\begin{array}{l}\text { Elevation of hypothalamic set point; calcium-channel } \\
\text { antagonism }\end{array}$ \\
\hline
\end{tabular}


Autonomic dysfunction in MSA can present as orthostatic intolerance, bladder dysfunction, erectile dysfunction, and also sudomotor dysfunction. ${ }^{7}$ An autonomic function test may be useful for distinguishing MSA from Parkinson's disease (PD), since autonomic dysfunction is more severe in MSA than in PD. ${ }^{8}$ Anhidrosis in a sudomotor function test is more widespread in MSA than in PD. ${ }^{9}$ Dementia with Lewy bodies (DLB) is another form of synucleinopathy that usually presents as distal anhidrosis. ${ }^{10}$ In addition to these degenerative diseases, structural lesions such as those associated with stroke, multiple sclerosis (MS), tumors, and infection can also cause anhidrosis when they involve autonomic pathways. ${ }^{11,12}$ Hyperthermia in MS involving autonomic sudomotor pathways may aggravate Uhthoff's phenomenon, which is characterized by the exacerbation of neurological symptoms. ${ }^{13}$

\section{Peripheral nervous system disorders}

\section{Pure autonomic failure (PAF)}

In contrast to MSA, PAF is known to be a peripheral autonomic neuropathy that mostly involves postganglionic autonomic fibers and ganglia. However, around 10\% of PAF patients show conversion to a central synucleinopathy (e.g., MSA, PD, or DLB) during long-term follow-up, and a preganglionic pattern of the sweat loss is particularly suggestive of the conversion to MSA. ${ }^{14}$

\section{Diabetes mellitus}

While sensorimotor polyneuropathy is one of the most-wellknown forms of diabetic complications, patients can also develop autonomic neuropathy, and this is known to be associated with mortality. ${ }^{15}$ Like sensorimotor polyneuropathy, the loss of sweating ability most commonly presents with a glove-stocking pattern, but can also be segmental or restricted to certain dermatomes. ${ }^{16}$

\section{Guillain-Barré syndrome (GBS)}

Autonomic function is readily overlooked in GBS, but its management is important in GBS patients since problems with autonomic function can lead to serious cardiovascular complications including hypertension, hypotension, and arrhythmia. ${ }^{17}$ Disturbance to sweating ability can also occur, but this is less common than other dysautonomic symptoms. ${ }^{18}$
Autoimmune autonomic ganglionopathy ( $A A G)$

AAG is an acquired autoimmune disease caused by antibodies against the nicotinic acetylcholine receptors in the autonomic ganglia. ${ }^{19}$ Immunotherapy (e.g., corticosteroid, intravenous immunoglobulin, or plasma exchange) is known to be effective for treating $A A G{ }^{20}$ Various symptoms of autonomic dysfunction may be apparent, and one study found anhidrosis to be the most-common symptom (presenting in $90 \%$ of cases). ${ }^{21}$

Other peripheral nervous system disorders

Anhidrosis can also develop in patients with amyloidosis, 22 alcoholic neuropathy, ${ }^{23}$ hereditary sensory and autonomic neuropathy, ${ }^{24}$ and Fabry disease. ${ }^{25}$ Fever due to sweating impairment is a common early symptom of Fabry disease, and this needs to be considered especially in the differential diagnosis of children with recurrent fever of unknown origin. ${ }^{25}$ In Ross syndrome, segmental anhidrosis is accompanied by tonic pupil and areflexia. ${ }^{26}$

\section{Dermatological disorders}

Congenital disorders such as ectodermal dysplasia or incontinentia pigmenti and acquired disorders such as miliaria or systemic sclerosis can cause atrophic changes in sweat glands or sweat ducts that result in anhidrosis.

\section{Acquired idiopathic generalized anhidrosis (AIGA)}

Cases of generalized anhidrosis without any of the etiologies discussed above can be diagnosed as AIGA. ${ }^{27}$ Recently published diagnostic guidelines indicate that AIGA can be diagnosed in cases satisfying both of the following criteria: 1) idiopathic anhidrosis with a broadly distributed nonsegmental spinal pattern, and with no other autonomic or neurological symptoms; and 2) anhidrosis observed across at least 25\% of the whole body area. ${ }^{2}$ AIGA generally develops at a young age with a relatively acute onset, can be accompanied by cholinergic urticaria, and responds well to corticosteroids (Fig. 1). ${ }^{28}$

\section{Evaluation of anhidrosis}

\section{Quantitative sudomotor axon reflex sweat test (QSART)}

The QSART evaluates the function of postganglionic sympathetic sudomotor axons, and is generally performed at 
the following four sites: forearm, proximal leg, distal leg, and foot. ${ }^{29}$ The basic principle of the test is as follows: acetylcholine permeates the skin via iontophoresis and binds to nicotinic receptors on sudomotor nerve terminals to induce an antidromic action potential that stimulates adjacent sudomotor nerve fibers and elicits an indirect sweat response. ${ }^{30}$ The increase in humidity due to sweating within the chamber of a capsule attached to the skin is recorded, and the sweat volume is measured and compared to normal values. This device was designed by the Mayo Clinic and is available as a commercial device (Q-Sweat, WR Medical Electronics, Stillwater, MN, USA). ${ }^{31}$

The QSART evaluates sudomotor function as part of autonomic function testing. Although the equipment is widely used in special autonomic nervous system laboratories, its expense makes it difficult to implement in a general clinical

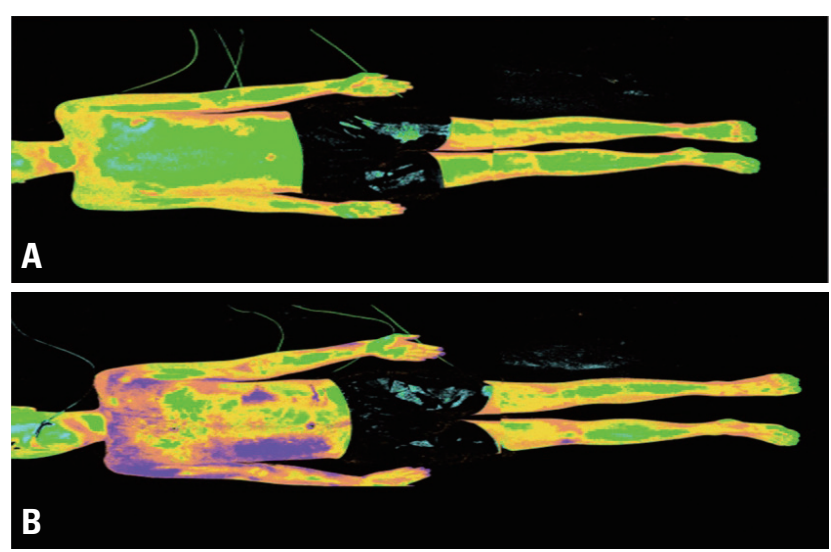

Fig. 1. Thermoregulatory sweat test results for a patient with acquired idiopathic generalized anhidrosis. (A) Sweating was absent from the entire skin. (B) Systemic corticosteroid therapy induced partial improvement of sweating (area indicated in purple). setting. In addition, because this test only evaluates postganglionic sudomotor function, it cannot be used to evaluate anhidrosis caused by preganglionic lesions; instead, it needs to be applied in combination with the thermoregulatory sweat test (TST) (as described below) in order to differentiate preganglionic and postganglionic anhidrosis (e.g., MSA and PD, respectively). ${ }^{5}$ Fig. 2 shows normal, length-dependent, and generalized anhidrosis results obtained in the QSART.

\section{Thermoregulatory sweat test}

While the QSART is only able to evaluate sweating in the area where the recording capsule is placed, TST is able to evaluate sweating across the entire skin (Fig. 1). The subject lies on a table in a chamber in which both the temperature and humidity are controlled. The core temperature is then increased to induce sweating, with the resulting change in an indicator dye being measured. ${ }^{32}$ Since this test evaluates both preganglionic and postganglionic sudomotor functions, it can be used in combination with the QSART to differentiate preganglionic and postganglionic deficits. However, the main drawback of this test is that, like the QSART, it requires special equipment.

\section{Sympathetic skin response (SSR)}

Unlike the above tests, the advantage of measuring the SSR is that it only requires standard electromyography equipment. After affixing surface electrodes to the soles and palms, electrical stimulation is applied to stimulate the sudomotor fibers, and the change in skin potential is recorded. ${ }^{33}$ However, the results of this test are highly variable, with habituation being unavoidable when making repeat measurements, and so the findings are typically based on the
A

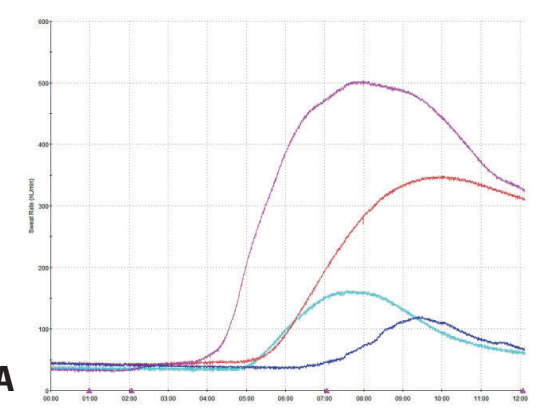

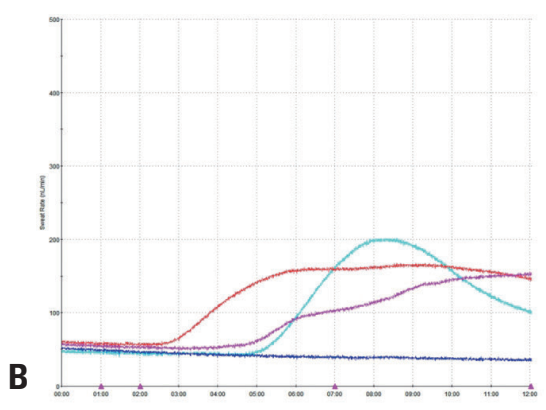

Fig. 2. Example results from quantitative sudomotor axon reflex sweat tests. Forearm, sky blue; proximal leg, red; distal leg, purple; foot, blue. (A) Normal results. (B) Diabetic neuropathy with length-dependent results. (C) Pure autonomic failure in the presence of generalized anhidrosis. 
presence or absence of a response, rather than a comparison with a reference range. This makes it difficult to quantitatively evaluate sudomotor function based on the SSR, and moreover individuals aged 50 years or older show no SSR, which makes it difficult to apply this test to the elderly. ${ }^{34}$

\section{Electrochemical skin conductance}

One advantage of measuring the electrochemical skin conductance is that this can be performed relatively conveniently using a Sudoscan device (Impeto Medical, Paris, France). The basic principle involves measuring the flow of chloride ions produced by sweat glands that have been activated by low-voltage electrical stimulation. ${ }^{35}$ However, there is still a lack of normative data, and so further research is required before this test can be used for quantitative evaluations. ${ }^{36,37}$

\section{Skin biopsy}

A skin biopsy is helpful not only for differentiating dermatological disorders, but also for identifying neuropathic conditions. The intraepidermal nerve fiber density (IENFD) is used as the gold standard for diagnosing small-fiber neuropathy. ${ }^{38,39}$ In addition to the IENFD, which measures sensory C-fibers, it is also possible to measure the density of nerve fibers innervating sweat glands, but this requires considerable time and effort. ${ }^{40}$ A skin biopsy of AIGA patients will reveal cellular infiltration around the sweat glands, sweat gland degeneration, and loss of nerve fibers around sweat glands. Depending on the pathological findings of such a biopsy, it is possible to distinguish sweat gland dysfunction, idiopathic pure sudomotor failure, and sudomotor neuropathy. ${ }^{41}$

\section{CONCLUSIONS}

Various neurological conditions and external factors such as medications need to be considered when diagnosing anhidrosis. There are several tests available for evaluating sweating, and the most-appropriate tests need to be selected according to the circumstances of individual hospitals.

\section{Conflicts of Interest}

The authors declare no competing financial interests.

\section{REFERENCES}

1. Chia KY, Tey HL. Approach to hypohidrosis. J Eur Acad Dermatol Venereol 2013;27:799-804.

2. Munetsugu T, Fujimoto T, Oshima Y, Sano K, Murota H, Satoh $T$, et al. Revised guideline for the diagnosis and treatment of acquired idiopathic generalized anhidrosis in Japan. J Dermatol 2017:44:394-400.

3. Sato K, Kang WH, Saga K, Sato KT. Biology of sweat glands and their disorders. I. normal sweat gland function. J Am Acad Dermatol 1989;20:537-563

4. Folk GE Jr, Semken HA Jr. The evolution of sweat glands. Int J Biometeorol 1991;35:180-186.

5. Low PA. Testing the autonomic nervous system. Semin Neurol 2003;23:407-421.

6. Cheshire WP, Fealey RD. Drug-induced hyperhidrosis and hypohidrosis: incidence, prevention and management. Drug Saf 2008;31:109-126.

7. Wenning GK, Colosimo C, Geser F, Poewe W. Multiple system atrophy. Lancet Neurol 2004;3:93-103.

8. Sandroni P, Ahlskog JE, Fealey RD, Low PA. Autonomic involvement in extrapyramidal and cerebellar disorders. Clin Auton Res 1991;1:147-155.

9. Lipp A, Sandroni P, Ahlskog JE, Fealey RD, Kimpinski K, lodice V, et al. Prospective differentiation of multiple system atrophy from Parkinson disease, with and without autonomic failure. Arch Neurol 2009;66:742-750.

10. Thaisetthawatkul P, Boeve BF, Benarroch EE, Sandroni P, Ferman TJ, Petersen $\mathrm{R}$, et al. Autonomic dysfunction in dementia with Lewy bodies. Neurology 2004;62:1804-1809.

11. Korpelainen JT, Sotaniemi KA, Myllylä W. Ipsilateral hypohidrosis in brain stem infarction. Stroke 1993;24:100-104.

12. Davis SL, Wilson TE, White AT, Frohman EM. Thermoregulation in multiple sclerosis. J Appl Physiol (1985) 2010;109:1531-1537.

13. Allen DR, Huang M, Parupia IM, Dubelko AR, Frohman EM, Davis SL. Impaired sweating responses to a passive whole body heat stress in individuals with multiple sclerosis. J Neurophysiol 2017;118:7-14.

14. Singer W, Berini SE, Sandroni P, Fealey RD, Coon EA, Suarez MD, et al. Pure autonomic failure: predictors of conversion to clinical CNS involvement. Neurology 2017;88:1129-1136.

15. Tesfaye S, Boulton AJM, Dyck PJ, Freeman R, Horowitz M, Kempler $P$, et al. Diabetic neuropathies: update on definitions, diagnostic criteria, estimation of severity, and treatments. Diabetes Care 
2010;33:2285-2293.

16. Fealey RD, Low PA, Thomas JE. Thermoregulatory sweating abnormalities in diabetes mellitus. Mayo Clin Proc 1989;64:617-628.

17. Zochodne DW. Autonomic involvement in Guillain-Barré syndrome: a review. Muscle Nerve 1994;17:1145-1155.

18. Anandan C, Khuder SA, Koffman BM. Prevalence of autonomic dysfunction in hospitalized patients with Guillain-Barré syndrome. Muscle Nerve 2017;56:331-333.

19. Manganelli F, Dubbioso R, Nolano M, lodice R, Pisciotta C, Provitera $\mathrm{V}$, et al. Autoimmune autonomic ganglionopathy: a possible postganglionic neuropathy. Arch Neurol 2011;68:504-507.

20. Iodice V, Kimpinski K, Vernino S, Sandroni P, Fealey RD, Low PA. Efficacy of immunotherapy in seropositive and seronegative putative autoimmune autonomic ganglionopathy. Neurology 2009;72:2002-2008.

21. Li Y, Jammoul A, Mente K, Li J, Shields RW, Vernino S, et al. Clinical experience of seropositive ganglionic acetylcholine receptor antibody in a tertiary neurology referral center. Muscle Nerve 2015:52:386-391.

22. Ohnishi A, Yamamoto T, Murai Y, Ando Y, Ando M, Hoshii Y, et al. Denervation of eccrine glands in patients with familial amyloidotic polyneuropathy type I. Neurology 1998;51:714-721.

23. Tugnoli V, Eleopra R, De Grandis D. Hyperhidrosis and sympathetic skin response in chronic alcoholic patients. Clin Auton Res 1999;9:17-22.

24. Hilz MJ. Assessment and evaluation of hereditary sensory and autonomic neuropathies with autonomic and neurophysiological examinations. Clin Auton Res 2002;12 Suppl 1:133-143.

25. Verrecchia E, Zampetti A, Antuzzi D, Ricci R, Ferri L, Morrone A, et al. The impact of fever/hyperthermia in the diagnosis of Fabry: a retrospective analysis. Eur J Intern Med 2016;32:26-30.

26. Weller M, Wilhelm H, Sommer N, Dichgans J, Wiethölter H. Tonic pupil, areflexia, and segmental anhidrosis: two additional cases of Ross syndrome and review of the literature. J Neurol 1992;239:231-234.

27. Chen YC, Wu CS, Chen GS, Khor GT, Chen CH, Huang P. Identification of subgroups of acquired idiopathic generalized anhidrosis. Neurologist 2008;14:318-320.

28. Nakazato Y, Tamura N, Ohkuma A, Yoshimaru K, Shimazu K.
Idiopathic pure sudomotor failure: anhidrosis due to deficits in cholinergic transmission. Neurology 2004;63:1476-1480.

29. Low PA, Tomalia VA, Park KJ. Autonomic function tests: some clinical applications. J Clin Neurol 2013;9:1-8.

30. Low PA. Evaluation of sudomotor function. Clin Neurophysiol 2004;115:1506-1513.

31. Sletten DM, Weigand SD, Low PA. Relationship of Q-sweat to quantitative sudomotor axon reflex test (QSART) volumes. Muscle Nerve 2010;41:240-246.

32. Illigens BM, Gibbons $\mathrm{CH}$. Sweat testing to evaluate autonomic function. Clin Auton Res 2009;19:79-87.

33. Elie B, Guiheneuc P. Sympathetic skin response: normal results in different experimental conditions. Electroencephalogr Clin Neurophysiol 1990;76:258-267.

34. Gibbons C, Freeman R. The evaluation of small fiber function-autonomic and quantitative sensory testing. Neurol Clin 2004;22:683-702, vii.

35. Casellini CM, Parson HK, Richardson MS, Nevoret ML, Vinik AI. Sudoscan, a noninvasive tool for detecting diabetic small fiber neuropathy and autonomic dysfunction. Diabetes Technol Ther 2013;15:948-953.

36. Buchmann SJ, Penzlin Al, Kubasch ML, Illigens BM, Siepmann T. Assessment of sudomotor function. Clin Auton Res 2018 May 8. [Epub]. DOl:10.1007/s10286-018-0530-2.

37. Novak P. Electrochemical skin conductance: a systematic review. Clin Auton Res 2017 Sep 26. [Epub]. DOI:10.1007/s10286-0170467-x.

38. Lauria G, Hsieh ST, Johansson O, Kenney WR, Leger JM, Mellgren $\mathrm{SI}$, et al. European Federation of Neurological Societies/Peripheral Nerve Society Guideline on the use of skin biopsy in the diagnosis of small fiber neuropathy. Report of a joint task force of the European Federation of Neurological Societies and the Peripheral Nerve Society. Eur J Neurol 2010;17:903-912, e44-e49.

39. Chan AC, Wilder-Smith EP. Small fiber neuropathy: getting bigger! Muscle Nerve 2016;53:671-682.

40. Sohn EH. Skin biopsy: an emerging method for small nerve fiber evaluation. Ann Clin Neurophysiol 2018;20:3-11.

41. Tay LK, Chong WS. Acquired idiopathic anhidrosis: a diagnosis often missed. J Am Acad Dermatol 2014;71:499-506. 